\title{
Anna Rogala
}

Uniwersytet Ekonomiczny w Poznaniu

e-mail: anna.rogala@ue.poznan.pl

\section{ZACHOWANIA INFORMACYJNE KONSUMENTÓW W PRZESTRZENI WIRTUALNEJ - SZANSE I ZAGROŻENIA}

\section{INFORMATION BEHAVIORS OF CONSUMERS IN VIRTUAL SPACE - OPPORTUNITIES AND THREATS}

DOI: $10.15611 /$ pn.2017.501.17

JEL Classification: D83, M31

Streszczenie: Celem rozważań podjętych w artykule jest analiza szans i zagrożeń związanych z zachowaniami informacyjnymi współczesnych konsumentów w przestrzeni wirtualnej. W oparciu o metodę desk research autorka dokonała przeglądu i krytycznej analizy źródeł literaturowych związanych z zachowaniami informacyjnymi, nowymi mediami oraz społeczno-kulturowymi konsekwencjami rozwoju technologii informacyjnych. W toku prowadzonych analiz dowiedziono, iż komunikacja w przestrzeni wirtualnej wzmacnia rolę i pozycję dotychczasowych odbiorców procesu, szybkość i łatwość dostępu do potrzebnych informacji. Jednocześnie w obrębie Internetu mają miejsce zjawiska ograniczające niezależność informacyjną konsumentów. $Z$ tego względu niezwykle ważne jest edukowanie w zakresie kompetencji i zachowań informacyjnych, a także kształtowanie postaw umożliwiających samodzielny, przemyślany wybór interesujących użytkownika treści oraz ich krytyczną interpretację.

Słowa kluczowe: zachowania informacyjne, komunikacja wirtualna, gatekeeping technologiczny.

Summary: The aim of the considerations is to analyze the opportunities and threats related to the information behaviors of contemporary consumers in virtual space. The paper is based on the desk research method. The author has reviewed and critically analyzed literature sources about information behaviors, new media and the socio-cultural implications of information technology development. In the course of the conducted analyzes, it has been proved that communication in the virtual space strengthens the role and position of the existing recipients of the process, speeds and eases the access to the information needed. At the same time, there are phenomena limiting the consumers' information independence within the Internet. For this reason, it is extremely important to educate in the field of information competences and behaviors, as well as to shape attitudes that enable independent, thoughtful choice of content of interest to the user and their critical interpretation.

Keywords: word communication behaviours, virtual communications, technological gatekeeping. 


\section{Wstęp}

Współczesne procesy komunikacji odbywają się w warunkach dominacji technologii informacyjnych. Istotnym przejawem ich oddziaływania jest rosnąca rola wirtualnych kanałów komunikacji z klientami, co sprawia, iż zwiększa się udział zachowań informacyjnych mających miejsce w Internecie w całości zachowań informacyjnych ludzi. Powoduje to określone konsekwencje dla procesów komunikacji, niosąc ze sobą wiele szans i udogodnień dla konsumentów. Z drugiej strony z takim stanem rzeczy wiążą się również zagrożenia, które powinny skłaniać do refleksji nad skutkami dominacji technologii w procesach komunikacji oraz niezależnością informacyjną konsumenta $\mathrm{w}$ przestrzeni wirtualnej. Celem rozważań podjętych w niniejszym artykule będzie analiza szans i zagrożeń związanych z zachowaniami informacyjnymi współczesnych konsumentów w Internecie.

\section{Zachowania informacyjne jako szerokie spektrum aktywności jednostek}

Każdy aspekt życia związany jest z wykorzystywaniem różnego rodzaju informacji pozyskiwanych i przetwarzanych w ramach zachowań informacyjnych. Stanowią one obszar dociekań badawczych przedstawicieli wielu dziedzin, m.in. psychologów, socjologów, medioznawców, kognitywistów czy informatologów [Kamińska-Czubała 2013, s. 18], i z tego powodu w piśmiennictwie są one niejednoznacznie definiowane. W powszechnie akceptowanej definicji zachowań informacyjnych autorstwa T. Wilsona podkreśla się, iż obejmują one wszystkie aktywności, działania oraz reakcje ludzi odnośnie do źródeł i kanałów informacji, przy czym podejście to zakłada, iż jednostka może być zarówno aktywna, jak i pasywna w poszukiwaniu oraz wykorzystaniu informacji [Wilson 2000, s. 49]. Co ważne, zachowania informacyjne mogą dotyczyć nie tylko jednej osoby, lecz cechować grupy ludzi, organizacje, a nawet warstwy społeczne.

Kategoria zachowań informacyjnych nie ogranicza się do działań (lub zaniechań) związanych z poszukiwaniem informacji, dlatego też istnieją różne typologie zaliczanych do niej aktywności. Ich zestawienie przedstawiono w tab. 1.

Wynika z niego, że do zachowań informacyjnych zalicza się cztery główne obszary, a mianowicie pozyskiwanie informacji, reagowanie na nie, indywidualne zarządzanie informacją oraz jej wykorzystanie. Z kolei w ramach każdego z obszarów wyróżnić można zachowania jednostek, takie jak np. rutynowe zbieranie informacji, unikanie jej czy ignorowanie, przetwarzanie, ale również dzielenie się nią z innymi. W związku z tym, badając zachowania informacyjne, odnosi się nie tylko do tego, jak konsument definiuje swoje potrzeby, ale także do formułowania potrzeb, poszukiwania i selekcji informacji oraz czynników wpływających na wspomniane procesy [Niedźwiedzka 2002]. 
Tabela 1. Typy zachowań informacyjnych

\begin{tabular}{|c|c|c|c|}
\hline $\begin{array}{l}\text { Pozyskiwanie } \\
\text { informacji }\end{array}$ & $\begin{array}{l}\text { Reagowanie na } \\
\text { informacje }\end{array}$ & $\begin{array}{c}\text { Indywidualne } \\
\text { zarządzanie } \\
\text { informacją }\end{array}$ & $\begin{array}{l}\text { Wykorzystanie } \\
\text { informacji }\end{array}$ \\
\hline $\begin{array}{l}\text { - aktywne, celowe } \\
\text { poszukiwanie } \\
\text { i gromadzenie } \\
\text { informacji } \\
\text { - rutynowe zbieranie } \\
\text { informacji } \\
\text { - przypadkowe } \\
\text { pozyskiwanie } \\
\text { informacji }\end{array}$ & $\begin{array}{l}\text { - dalsze poszukiwanie } \\
\text { wiadomości } \\
\text { - tzw. taking } \\
\text { mental note, } \\
\text { czyli zachowanie } \\
\text { w pamięci „na } \\
\text { wszelki wypadek” } \\
\text { - unikanie lub } \\
\text { ignorowanie } \\
\text { informacji } \\
\text { - niezgoda } \\
\text { lub niewiara } \\
\text { w informację } \\
\text { ukrywanie } \\
\text { lub niszczenie } \\
\text { informacji } \\
\text { zrozumienie } \\
\text { informacji, } \\
\text { włączenie jej } \\
\text { w struktury } \\
\text { dotychczasowej } \\
\text { wiedzy użytkownika }\end{array}$ & $\begin{array}{ll}\text { - } & \text { ocena i selekcja } \\
\text { informacji } \\
\text { - } \\
\text { opracowanie } \\
\text { informacji } \\
\text { - } \\
\text { przetwarzanie } \\
\text { informacji } \\
\text { przechowywanie } \\
\text { informacji }\end{array}$ & $\begin{array}{l}\text { - dzielenie się } \\
\text { informacją z innymi, } \\
\text { przekazywanie, } \\
\text { upowszechnianie } \\
\text { (information } \\
\text { exchange, sharing, } \\
\text { transfer) } \\
\text { - podjęcie decyzji } \\
\text { w oparciu } \\
\text { o informację } \\
\text { rozwiązanie } \\
\text { problemu, } \\
\text { wykonanie zadania, } \\
\text { „załatwienie } \\
\text { sprawy" } \\
\text { odzyskanie albo } \\
\text { ustanowienie } \\
\text { poczucia sensu } \\
\text { rzeczywistości }\end{array}$ \\
\hline
\end{tabular}

Źródło: opracowanie własne na podstawie [Goldbold 2006; Cisek 2017].

Należy podkreślić, iż aby zachowania informacyjne przynosiły ludziom oczekiwane efekty i korzyści, niezbędne są rozwinięte kompetencje informacyjne, umożliwiające nie tylko znalezienie konkretnych treści, ale także, a może przede wszystkim, ich krytyczną analizę, wybór oraz wartościowanie. Zagadnienia te są szczególnie istotne z punktu widzenia tematyki podjętej w artykule (szerzej na ich temat w kolejnych punktach artykułu).

\section{Komunikacja w przestrzeni wirtualnej- szanse i udogodnienia dla konsumentów}

Dzięki dynamicznemu rozwojowi technologii współczesne procesy informacyjne i komunikacyjne charakteryzuje możliwość korzystania z wielu narzędzi i kanałów. Cechuje je szybkość, interaktywność, ale przede wszystkim łatwość oraz wygoda dostępu zarówno dla nadawców, jak i odbiorców. W szczególności zależności te dotyczą komunikacji w przestrzeni wirtualnej. Niemal powszechny dostęp do Internetu pozwala konsumentom na szybkie pozyskanie interesujących/potrzebnych 
informacji, ich weryfikację, a także podjęcie działań związanych np. z zakupem konkretnego produktu. Dodatkowo urządzenia mobilne zwiększają częstość oraz przejawianie w czasie rzeczywistym zachowań informacyjnych, inicjowanych przez różne impulsy, w tym także przez potrzeby nabywców. Według raportów z serii „Digital” przygotowywanych przez We Are Social i Hootsuite penetracja Internetu wynosi w Polsce obecnie $77 \%$ czyli o $10 \%$ więcej niż jeszcze rok temu. Polacy spędzają codziennie w przestrzeni wirtualnej 5 godzin i 43 minuty, korzystając z komputera lub tabletu, oraz 1 godzinę i 33 minuty na innych urządzeniach mobilnych [Kemp 2016b; Kemp 2017b]. Te ostatnie są używane do komunikacji (np. w mediach społecznościowych), oglądania filmów, grania w gry mobilne, a także korzystania z usług bankowości mobilnej czy serwisów nawigacji i map (por. [Kemp 2016a; Kemp 2017a]).

W przypadku komunikacji wirtualnej, częściej niż na innych płaszczyznach, zaobserwować można zmianę paradygmatu odbiorcy przekazów. Publiczność traktuje się obecnie raczej jako aktywnego twórcę znaczenia niż biernego adresata procesów komunikacyjnych [Rogala 2017]. Dla przykładu w tradycyjnych mediach większość treści tworzona była przez nadawców, w dość ograniczonym zakresie, umożliwiając ich współtworzenie odbiorcom. Tymczasem rewolucja internetowa doprowadziła do nowego podziału wpływów na polu komunikacyjnym, umacniając pozycję konsumentów i pozwalając na zacieśnianie współpracy z oferentami dóbr i usług.

Na podkreślenie zasługuje również fakt, iż Internet jest medium egalitarnym, społecznościowym i wolnościowym. Dzięki temu jednostki samodzielnie decydują o kwalifikowaniu poszczególnych informacji do kategorii ważnych i wartych rozpowszechnienia [Szpunar 2013, s. 60]. Zyskały one również możliwość demaskowania nieprawdziwych informacji podawanych w mediach tradycyjnych czy wyrażania protestu przeciwko niepokojącym ich zjawiskom [Tarasewicz-Gryt 2013, s. 101]. Dodatkowo wirtualne platformy komunikacyjne, powstałe wskutek przemian społecznych i technologicznych, są obecnie miejscem tworzenia się opiniotwórczych grup (społeczności). Charakteryzują je duży potencjał i siła oddziaływania na innych konsumentów. Wspomniane społeczności tworzą czy współtworzą treści interesujące z punktu widzenia wchodzących w ich skład jednostek. Zajmują się również interpretacją, selekcją i przekazywaniem członkom docierających do nich informacji. W czasach upływających pod znakiem natłoku, szumu i przeciążenia informacyjnego prowadzi to do oszczędności czasu przeznaczonego na zachowania informacyjne poszczególnych osób wchodzących w skład społeczności.

Bardzo ważną zaletą Internetu jako medium komunikacji jest również możliwość prowadzenia szybkiej, ciągłej konwersacji, bez względu na odległość, w jakiej znajdują się strony procesu [Szpunar 2004]. Podkreśla się również, iż Internet wzmacnia perswazyjną siłę użytkowników, gdyż umożliwia im łatwiejsze przywołanie racjonalnych argumentów w komunikacji wirtualnej [Tarasewicz-Gryt 2013, s. 98]. Odbywa się to w formie przekazywania linków do oficjalnych danych liczbowych, wypowiedzi autorytetów czy sondaży opinii. 


\section{Negatywne konsekwencje dominacji technologii w procesach komunikacji}

Korzystając z dobrodziejstw, jakie niesie komunikacja wirtualna, wiele osób nie uświadamia sobie zagrożeń związanych z korzystaniem z nowoczesnych technologii komunikacyjnych. Tymczasem mają one istotny wpływ na niezależność informacyjną konsumentów. Warto poddać je bardziej szczegółowej analizie, by móc ograniczać ich negatywne oddziaływanie w procesach zachowań informacyjnych.

Pierwsze z zagrożeń związane jest ze zjawiskiem gatekeepingu publiczności, który wskazuje na kluczową rolę użytkowników w procesie redystrybucji i produkcji treści oraz ich przekazywaniu do innych odbiorców [Shoemaker, Vos 2009]. Co prawda, niesie ono ze sobą istotne korzyści, jednak należy mieć na uwadze również fakt, iż przeciążenie informacyjne może zniechęcić konsumentów do samodzielnego poszukiwania informacji i sprawić, że będą opierać się w większości lub wyłącznie na tych, które zostały przekazane im przez selekcjonerów wirtualnych społeczności, zgodnie z ideą rozprzestrzenialnych mediów [Filiciak i in. 2010, s. 137]. Z kolei ci ostatni w większości kierować będą się własnym interesem i subiektywną oceną przekazywanych przez siebie treści. W przestrzeni wirtualnej obserwuje się już bowiem zjawisko kategoryzowania treści, nadawania im priorytetów i określonego sensu przez platformy społeczne. Efekt ten jest również związany z zasadą minimalizacji wysiłku, zgodnie z którą ludzie preferują schematy postępowania oraz źródła znane, wypróbowane, łatwo dostępne i przyjazne w użyciu nawet wtedy, gdy są one postrzegane jako gorszej jakości [Cisek 2017, s. 7].

Kolejnym z zagrożeń w komunikacji wirtualnej jest gatekeeping technologiczny związany z wyszukiwaniem informacji przez wyszukiwarki internetowe. Jeszcze do niedawna były one uznawane za technologie neutralne, ułatwiające użytkownikom znajdowanie interesujących ich treści. Tymczasem w rzeczywistości są kolejnym selekcjonerem przekazów i w sposób istotny wpływają na to, jakie informacje trafiają do odbiorców. Zdaniem niektórych badaczy podobną rolę odgrywają media społecznościowe [Helberger, Kleinen-von Königslöw, van der Noll 2015, s. 51]. Co ważne, personalizacja wyszukiwań, tak ceniona przez większość użytkowników Internetu, nie jest wyłącznie wynikiem działania algorytmów, ale także człowieka nadzorującego działanie wyszukiwarki czy platformy społecznościowej. Może on wpływać na to, jakie treści są dostępne dla odbiorców nie tylko przez odpowiednie zaprojektowanie algorytmu, ale także ręczne sterowanie [Bozdag 2013, s. 209]. Dodatkową konsekwencją personalizacji jest to, że wyniki wyszukiwań zwracane internaucie $\mathrm{w}$ ramach jego zapytania są $\mathrm{w}$ dużym stopniu związane $\mathrm{z}$ historią wcześniejszych wyszukiwań. Jak wskazuje E. Pariser [2011], może to prowadzić do wykształcenia się monokultur, w których użytkownicy zostają uwięzieni w tzw. bańce filtrującej, ze znacznie ograniczonymi możliwościami w ramach niezależnych zachowań informacyjnych. Należy zatem unikać zarówno bierności informacyjnej, jak i bezkrytycz- 
ności w odniesieniu do treści promowanych przez wyszukiwarki jako znalezione specjalnie dla nas.

$\mathrm{Z}$ poszukiwaniem informacji w przestrzeni wirtualnej wiążą się również różne podejścia do tego procesu. Badaczka J. Heinström, analizując sposoby zdobywania informacji naukowej w środowisku elektronicznym przez magistrantów, wyróżniła trzy podejścia [Heinström 2005]: fast surfing, broad scanning i deep diving. Pierwsze z nich polega na pospiesznym i niedbałym wyszukiwaniu treści. Poszukujący nie przywiązuje większej wagi do oceny pozyskanych informacji i preferuje zasoby, które potwierdzają jego wcześniejsze poglądy i wiedzę. Nie jest zainteresowany treściami ukazującymi problem w innym świetle. Takie podejście występuje często w sytuacji braku czasu. Z kolei tzw. broad scanning związany jest ze starannym, szerokim i wielopłaszczyznowym poszukiwaniem informacji, z wykorzystaniem wielu różnorodnych źródeł on-line. Treści pozyskiwane są na zasadzie przypadku, ale podmiot poddaje je krytycznej ocenie. Natomiast deep diving zakłada drobiazgowe i precyzyjne „dokopywanie się" do informacji, przy czym odbywa się ono w oparciu o wypracowaną strategię wyszukiwawczą. Dodatkowo poszukujący akceptuje wyłącznie takie źródła i treści, które uzna za charakteryzujące się wysoką jakością. W praktyce zachowań informacyjnych związanych z poszukiwaniem potrzebnych treści fast surfing dominujące nad broad scanning i deep diving.

Wśród niepokojących zjawisk wymienić należy również nieodpowiedni model konsumpcji Internetu, wynikający z zakorzenionych praktyk kulturowych. Internauci rzadko kierują się bowiem twórczymi możliwościami, jakie daje to medium [Szpunar 2012, s. 197]. W większości nie potrafią lub nie chcą aktywnie tworzyć przestrzeni wirtualnej, ograniczając się do biernej konsumpcji bez zaangażowania w zarządzanie tym obszarem komunikacji. W konsekwencji medium, z założenia interaktywne, prowadzi do reaktywności. Przez szybkość, powszechność i łatwość dostępu Internet staje się bankiem pamięci, który zwalnia z procesu zapamiętywania czegoś więcej niż to, gdzie dana informacja się znajduje [Szpunar 2012, s. 198].

Ostatnim z zagrożeń zachowań informacyjnych w przestrzeni wirtualnej jest nieodpowiednie gospodarowanie czasem wolnym, zwłaszcza wśród ludzi młodych. Pogrążanie się w cyfrowym świecie, który jest uproszczoną i upiększoną wersją świata rzeczywistego, budzi niepokój [Kamińska-Czubała 2013, s. 22]. Podkreśla się bowiem, że człowiek jako użytkownik informacji powinien prowadzić zrównoważone życie w każdej ze sfer. Badaniem tego zjawiska zajmują się ekologowie informacji.

\section{Podsumowanie}

Komunikacja w przestrzeni wirtualnej niesie ze sobą wiele udogodnień i szans dla jej uczestników, jak chociażby wzmocnienie roli i pozycji dotychczasowych odbiorców procesu czy szybkość i łatwość dostępu do potrzebnych informacji. Jednocześnie w obrębie Internetu, będącego z założenia medium egalitarnym, wolnościowym i interaktywnym, zachodzą zjawiska ograniczające niezależność informacyjną 
konsumentów, zachęcające do biernej jego konsumpcji czy pozbawiające jednostki możliwości wyboru. Dodatkowo nadmiar informacji w tym kanale znacznie utrudnia ich racjonalne wykorzystanie. $Z$ tego względu w czasach zdominowanych przez nowoczesne technologie komunikacyjne i informacyjny nadmiar najważniejsze jest edukowanie w zakresie kompetencji i zachowań informacyjnych oraz kształtowanie postaw umożliwiających samodzielny, przemyślany wybór interesujących użytkownika Internetu treści oraz ich krytyczną interpretację.

\section{Literatura}

Bozdag E., 2013, Bias in algorithmic filtering and personalization, Ethics and Information Technology, September 2013, 15:209-227, DOI 10.1007/s10676-013-9321-6.

Cisek S., 2017, Zachowania informacyjne - wybrane aspekty, Biuletyn EBIB, nr 3 (173).

Godbold N., 2006, Beyond information seeking: towards a general model of information behavior, Information Research, vol. 11 no. 4, paper 269, http://InformationR.net/ir/11-4/paper269.html (7.06.2017).

Filiciak M. Danielewicz M., Halawa M. Mazurek P., Nowotny A., 2010, Młodzi i media. Nowe media a uczestnictwo w kulturze, Raport Centrum Badań nad Kulturą Popularną, SWPS, Warszawa.

Heinström J., 2005, Fast surfing, broad scanning and deep diving: The influence of personality and study approach on students' information-seeking behavior, Journal of Documentation, 61, 2, s. 228-247.

Helberger N., Kleinen-von Königslöw K., van der Noll R., 2015, Regulating the new information intermediaries as gatekeeper of information diversity, Digital Policy, Regulation and Governance, vol. 17, issue 6, s. 50-71, https://doi.org/10.1108/info-05-2015-0034.

Kamińska-Czubała B., 2013, Zachowania informacyjne w życiu codziennym. Informacyjny świat pokolenia $Y$, Wydawnictwo SBP, Warszawa

Kemp S., 2016a, 2016 Digital Yearbook, We Are Social. Hootsuite, https://mobirank.pl/2016/01/27/ mobile-digital-w-polsce-na-swiecie-2016/, (8.09.2017).

Kemp, S., 2016b, Digital in 2016. Global Overview, We Are Social. Hootsuite, https://mobirank. pl/2016/01/27/mobile-digital-w-polsce-na-swiecie-2016/ (8.09.2017).

Kemp S., 2017a, 2017 Digital Yearbook, We Are Social. Hootsuite, https://www.slideshare.net/ wearesocialsg/2017-digital-yearbook?ref=https://wearesocial.com/uk/?p=44702\&preview=true (8.09.2017).

Kemp S., 2017b, Digital in 2017. Global Overview, We Are Social. Hootsuite. https://wearesocial.com/ uk/special-reports/digital-in-2017-global-overview (8.09.2017).

Niedźwiedzka B., 2002, Modyfikacja modelu zachowań informacyjnych T.D. Wilsona w świetle wyników badania zachowań informacyjnych menedżerów, Zagadnienia Informacji Naukowej, nr 1.

Pariser E., 2011, The Filter Bubble: What the Internet is Hiding from You, Penguin Press, London.

Rogala A., 2017, Komunikacja marketingowa w społeczeństwie sieci-ewolucja czy rewolucja?, Przedsiębiorczość i Zarządzanie, Wydawnictwo Społecznej Akademii Nauk w Łodzi, Łódź.

Shoemaker P., Vos T., 2009, Gatekeeping Theory, Routledge, New York.

Szpunar M., 2004, Społeczności wirtualne jako społeczności - próba ujęcia socjologicznego, [w:] Jednostka - grupa - cybersieć. Psychologiczne, społeczno-kulturowe i edukacyjne aspekty społeczeństwa informacyjnego, M. Radochoński, B. Przywara (red.), WSIiZ, Rzeszów.

Szpunar M., 2013, Wokót koncepcji gatekeepingu. Od gatekeepingu tradycyjnego do technologicznego. Idee i myśliciele, Wydawnictwo Akademii Górniczo-Hutniczej, Kraków. 
Szpunar M., 2012, Nowe - stare medium. Internet między tworzeniem nowych modeli komunikacyjnych a reprodukowaniem schematów komunikowania masowego, Wydawnictwo IFiS PAN, Warszawa.

Tarasewicz-Gryt O., 2013, Stare czy nowe? Retoryka nowych mediów, [w:] Nowe media a praktyki komunikacyjne, K. Pokorna-Ignatowicz, S. Jędrzejewski, J. Bierówka (red.), Krakowska Akademia im. Andrzeja Frycza Modrzewskiego, Kraków.

Wilson T.D., 2000, Human information behavior, Informing Science. Informing Science, vol. 3, no. 2000, http://inform.nu/Articles/Vol3/v3n2p49-56.pdf (10.09.2017). 